The remit of the group was to work collaboratively with partners and service users to produce an informative learning tool to support others in setting up a telephone triage service.

The production of the DVD and accompanying training package brought many positives, from the benefits of partnership working to demonstrate the value of services were clearly evident, to the role of education in sharing ideas and best practice. Most importantly though, the project gave us hope that in developing an educational tool to facilitate the sharing of our innovative service design, we would be playing a part - albeit a small one - in advancing rapid access to palliative care and improving outcomes for patients.

\title{
P108 SHARING INNOVATION TO IMPROVE ACCESS TO SPECIALIST PALLIATIVE CARE: MAKING A TRIAGE DVD TRAINING TOOL
}

Lesley Burrows, Louise Toland, Sarah Godfrey, Michaela Sen, Yvonne Miah Saint Francis Hospice, Essex, UK

The widening access agenda and quest to extend palliative care services to all has resulted in a significant increase in referrals for community support. Working innovatively to create flexible, accessible and responsive services to meet increasing demand, our hospice developed an enhanced telephone triage service.

The telephone triage service plays an invaluable role in providing high quality specialist palliative care advice to increasing numbers of patients in the community. Audit of the clinical activity of both our community palliative care and triage services demonstrates that the addition of the telephone triage service has enabled us to deliver quality specialist support to $67 \%$ more patients in the community.

The success of the service and the outcomes it achieves has attracted much interest from other providers of palliative care. Requests for information, and for facilitated visits to observe the service in action were so frequent that we decided to produce a DVD and accompanying training package to support others in establishing a similar service.

A project group was formed to guide DVD production from the writing of the bid, to the marketing of the final product. 